\title{
Incidence of Tobacco Related White Lesions in Patients
}

Keerthana Baskar ${ }^{1}$, Maragathavalli $\mathrm{G}^{2}$, Sreedevi Dharman ${ }^{3}$

${ }^{1}$ Saveetha Dental College and Hospitals, Saveetha Institute of Medical and Technical Sciences, Saveetha University, Chennai, India.

${ }^{2}$ Professor, Department of Oral medicine \& Radiology, Saveetha Dental College and Hospitals, Saveetha Institute of Medical and Technical Sciences, Saveetha University, Chennai, 600077, India.

${ }^{3}$ Reader, Department of Oral medicine \& Radiology, Saveetha Dental College and Hospitals, Saveetha Institute of Medical and Technical Sciences, Saveetha University, Chennai, 600077, India.

\section{Abstract}

Usage of tobacco has been a common habit in India. It is positively associated with lesions in the oral cavity. No study has been conducted in this part of Tamil Nadu regarding this.The aim of this study is to evaluate the incidence of tobacco related white lesions in patients. A hospital based study was carried out at private dental college. The data of patients with tobacco related white lesions was obtained by reviewing the case sheets. The data was tabulated and statistical analysis was done by SPSS software version 19. Of the five lesions that were studied, it was found that tobacco pouch keratosis had the highest incidence rate of $33.42 \%$, followed by leukoplakia $25.8 \%$, Oral submucous fibrosis $24.02 \%$, Stomatitis nicotina $14.6 \%$ followed by lichenoid reaction is $2.1 \%$, The lesions were more prevalent in males than females. The incidence of premalignant lesions were more than other white lesions. Hence tobacco cessation programmes should be conducted to educate the people.

Keywords: Oral Lesions; Prevalence; Smokeless Tobacco; White Lesions.

\section{Introduction}

Oral cavity is prone to great changes with advancing age, as well as due to environmental and lifestyle factors. Oral mucosal lesions occur as a result of infection, local trauma, irritation, systemic diseases, lifestyle factors such as tobacco consumption, betel quid chewing and alcohol [1].

Smoking and chewing of tobacco along with the consumption of alcoholic beverages, has become a very popular social habit in India [2]. India has the second largest producer and consumer of tobacco following China [3, 4]. The prevalence of tobacco use among Indians is about 35\%, as cited in the previous literature [5].

Tobacco, initially was used to smoke in India, that later began to be used in several forms such as Paan (betel quid) chewing and leaf tobacco [6]. The most important ingredient of tobacco leaves is nicotine, a volatile alkaloid [7]. In India, the most commonly used smoking form of tobacco is beedi and chewing form is paan.
OSCC can occur even in the absence of tobacco usage [8].

White lesions are present commonly in the oral cavity. They appear white because the abnormal keratin reflects the spectrum of light evenly and due to the constant beating of the hyperkeratotic tissue in saliva, analogous to the appearance of palms and soles when immersed in water for a very long period of time $[9,10]$.

Tobacco related white lesions include leukoplakia, oral submucous fibrosis, oral lichen planus, tobacco pouch keratosis and nicotina stomatitis. White lesions in the oral cavity may be benign, premalignant or malignant. Leukoplakia, oral submucous fibrosis and lichenoid reaction are premalignant lesions that have the potential for malignant transformation [2]. Various habits such as smoking, tobacco chewing, or stress cause early tissue changes that are considered to be oral premalignant disorders. These disorders have a high potential to turn into malignancy $[11,12]$. Metastatic malignancies of the oral mucosa account only for about $1-4 \%$ of all oral malignancies. Primary squamous cell carcinoma is the most prevalent malignancy [13]. Oral mucositis, a common side effect

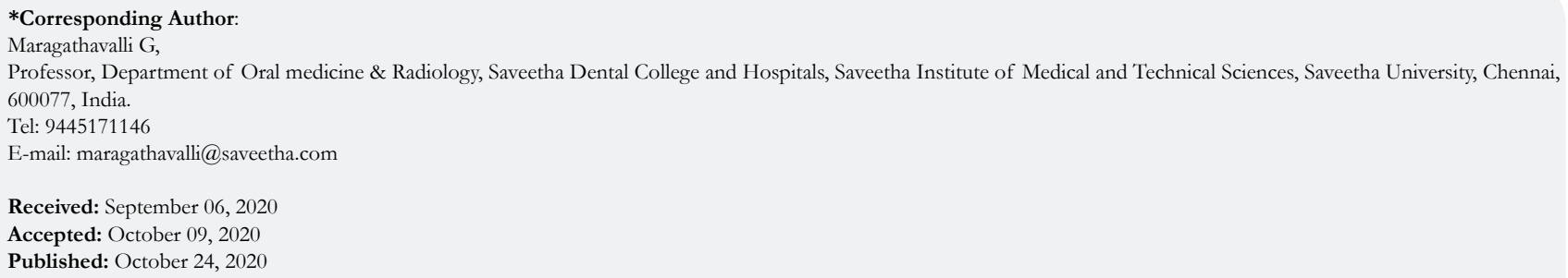

Copyright: Maragathavalli $\mathbf{G}^{\circ}$ 2020. This is an open-access article distributed under the terms of the Creative Commons Attribution License, which permits unrestricted use, distribution and reproduction in any medium, provided the original author and source are credited. 
of radiotherapy, given to patients with cancer [14]. Although there are various advances in health care, management of postoperative pain remains a difficult task for healthcare providers [15].

It has been a very common practice to classify the majority of lesions as 'leukoplakia', that literally means 'white plaque'.

There are no signs and symptoms that can predict if a premalignant lesion may change malignant or not. Hence a thorough history taking, physical examination, blood investigation and biopsy play a pivotal role in proper and efficient diagnosis. The scope of oral medicine practice varies greatly between different countries [16].

Various clinical trials, surveys and reviews have been conducted by our team [17-23]. The aim of this paper is to study the incidence of tobacco related white lesions in patients.

\section{Materials and Methods}

A hospital based study was done in a private dental college, Chennai. The ethical approval was procured from the Institutional Research Board.(SDC/SIHEC/2020/DIASDATA/0619-0320). Sampling was done from June 2019-April 2020. A sample of 384 patients was taken. Sampling was down from June 2019-April 2020. Patients with tobacco related white lesions that included leukoplakia, lichenoid reaction, oral submucousfibrosis, nicotina stomatitis and tobacco pouch keratosis were included. To minimise sampling bias, simple random sampling was done. Cross verification was done by photographs. The data was transferred to excel and tabulated. The data was analysed. Incomplete and censored data was removed. The data was imported to SPSS ver- sion [19]. Frequency of the white lesions was estimated and chisquare test was performed for gender association of the lesions. The independent variables in the study were age and gender, and the dependent variable was the white lesion present in tobacco consuming patients.

\section{Results and Discussion}

In this study, there were 20 female patients and 363 male patients out of the total 383 patients. From this study, it is evident that the most common white lesion present among patients who consume tobacco was tobacco pouch keratosis. (33.42\%) It was also found that males were affected more commonly than females $(32.11 \%)$. Oral submucous fibrosis was the most common white lesion found among females $(1.83 \%)$. Frequency of leukoplakia is $25.85 \%$, being the second most common lesion. The prevalence of lichenoid reaction is $2.09 \%$ which is comparatively much lesser than other oral lesions. There is no significant difference between males and females associated with lichenoidreaction. Oral submucous fibrosis was present in $24.02 \%$ of the individuals. Stomatitis nicotina was present in $14.62 \%$ of patients. No females were associated with stomatitis nicotina.

In the present study, the prevalence of tobacco about keratosis was found to be the most common $(33.42 \%)$. In a study conducted by Saraswati et al., it was found that smokers' melanosis was the most common lesion (1.14\%), that is not in accordance with the present study. The prevalence of smokers palette in this study is $14.6 \%$. In a study conducted by Chandra el al, The prevalence was found to be $4.6 \%$ [24]. Studies done in western population, showed a much lesser prevalence rate $[25,26]$. No females had smokers palate in our study.

Figure 1. Bar graph shows the frequency distribution of tobacco related white lesions. The X-axis denotes oral lesion and Y-axis denotes number of patients. Tobacco pouch keratosis (brown) was present predominantly in patients (33.42\%).

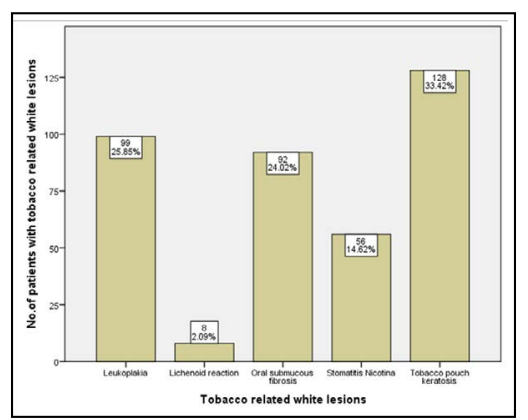

Figure 2. The bar graph shows association between tobacco related white lesion and gender. The $\mathrm{X}$-axis denotes white lesion with gender and Y-axis denotes the number of patients. All white lesions were more prevalent in males (green) than in females (blue). Chi square test was done and association was found to be statistically significant. Pearson's Chi Square value: 21.439 , df:4, p value: $0.000(<0.05)$. There is a significant association between gender and the occurrence of tobacco related white lesions.

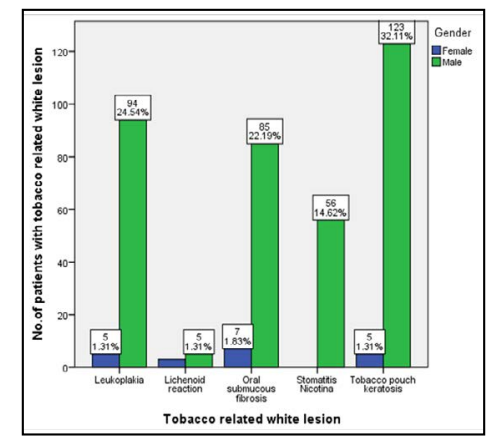


OSMF is a high-risk precancerous condition of the oral mucosa seen in India which is due to the beetle chewing population. In our study the prevalence was $24.3 \%$. The prevalence in Saraswati et al and Chandra et al was significantly less compared to the present study $[2,24]$.

Oral lichenoid reactions are considered as oral variants of lichen planus. The prevalence of tobacco related lichenoid reaction in our study was found to be $2.1 \%$. Similar results were obtained by Ismail at all [27]. There was no significant difference between male and female patients with lichenoid reaction in the present study.

Tobacco pouch keratosis results due to the placement of tobacco that causes play acidity in chronically stretched tissue in the area of placement of tobacco. In our study the prevalence of tobacco pouch keratosis was the highest, $33.42 \%$. In a study by Neville et al, the prevalence rates were much lower [28]. The prevalence of tobacco pouch keratosis was significantly much higher in men $(32.11 \%)$

Leukoplakia, a premalignant lesion Associated with smoke and smokeless form of tobacco, had a prevalence of $25.8 \%$, the second most common white lesion in the oral cavity. In a study by Chandra et al, the prevalence was found to be 3.5\% which was significantly much lesser [24]. Saraswati et al, also found that leukoplakia was the second most common white lesion in the study which is in accordance with our study [2]. In the present study leukoplakia was present more in males than in females.

The limitation of the study is that age variation of the lesion was not studied and the type of tobacco used resulting in the lesion was not studied.

\section{Conclusion}

Within the limitations of the study, it was found that the incidence of tobacco pouch keratosis was most common, followed by leukoplakia both being premalignant lesions. All the tobacco related white lesions were also commonly associated with males. Tobacco cessation programmes and public health programmes should be conducted to increase the awareness on the harmful effects caused and to advise them to cessate the habit.

\section{Acknowledgement}

This study was supported by Saveetha Dental College and Hospitals, providing insights and expertise that greatly assisted the study. We would also like to thank the reviewers of the article for the valuable insights provided by them.

\section{References}

[1]. Patel P, Patel V. Oral mucosal lesions among residence of a town in north Gujarat. Natl J Med Res. 2011;1(1):3-6.

[2]. Saraswathi TR, Ranganathan K, Shanmugam S, Sowmya R, Narasimhan PD, Gunaseelan R. Prevalence of oral lesions in relation to habits: Cross-sectional study in South India. Indian J Dent Res. 2006 Jul-Sep;17(3):121-5. PMID: 17176828

[3]. Kaur J, Jain DC. Tobacco control policies in India: implementation and challenges. Indian J Public Health. 2011 Jul-Sep;55(3):220-7. PMID: 22089690
[4]. World Health Organization. Fresh and alive: Mpower, WHO report on the global tobacco epidemic, 2008. World Health Organization. 2008.

[5]. Pharmacopoeia I. Government of India, ministry of health and family welfare. Delhi: Controller of Publications. 1996;2(35):448.

[6]. Reddy KS, Gupta PC. Economic History of tobacco production: From colonial origins to contemporary trends. Report on Tobacco Control in India. Joint Report Supported by Ministry of Health and Family Welfare, Government of India, Centre of Disease Control and Prevention. USA: World Health Organization. 2004;2:19-32.

[7]. Muthukrishnan A, Warnakulasuriya S. Oral health consequences of smokeless tobacco use. Indian J Med Res. 2018 Jul;148(1):35-40. PMID: 30264752 .

[8]. Muthukrishnan A, Bijai Kumar L. Actinic cheilosis: early intervention prevents malignant transformation. BMJ Case Rep. 2017 Mar 20;2017:bcr2016218654. PMID: 28320702.

[9]. Payne TF. Why are white lesions white? Observations on keratin. Oral Surg Oral Med Oral Pathol. 1975 Nov;40(5):652-8. PMID: 52857.

[10]. Tong DC, Ferguson MM. A clinical approach to white patches in the mouth. NEW ZEALAND FAMILY PHYSICIAN. 2002;29(5):334-9.

[11]. Venugopal A, Uma Maheswari TN. Expression of matrix metalloproteinase-9 in oral potentially malignant disorders: A systematic review. J Oral MaxillofacPathol. 2016 Sep-Dec; 20(3): 474-479. PMID: 27721614.

[12]. Maheswari TNU, Venugopal A, Sureshbabu NM, Ramani P. Salivary micro RNA as a potential biomarker in oral potentially malignant disorders: A systematic review. Ciji Yi XueZaZhi. 2018 Apr-Jun;30(2):55-60. PMID: 29875583.

[13]. Misra SR, Shankar YU, Rastogi V, Maragathavalli G. Metastatic hepatocellular carcinoma in the maxilla and mandible, an extremely rare presentation. ContempClin Dent. 2015 Mar;6(Suppl 1):S117-21. PMID: 25821363

[14]. Chaitanya NC, Muthukrishnan A, Babu DBG, Kumari CS, Lakshmi MA, Palat G, et al. Role of Vitamin E and Vitamin A in Oral Mucositis Induced by Cancer Chemo/Radiotherapy- A Meta-analysis. J ClinDiagn Res. 2017 May;11(5):ZE06-ZE09. PMID: 28658926.

[15]. Chaitanya NC, Muthukrishnan A, Krishnaprasad CMS, Sanjuprasanna G, Pillay P, Mounika B. An Insight and Update on the Analgesic Properties of Vitamin C. J Pharm Bioallied Sci. 2018 Jul-Sep;10(3):119-125. PMID: 30237682 .

[16]. Steele JC, Clark HJ, Hong CH, Jurge S, Muthukrishnan A, Kerr AR, et al. World Workshop on Oral Medicine VI: an international validation study of clinical competencies for advanced training in oral medicine. Oral Surg Oral Med Oral Pathol Oral Radiol. 2015 Aug;120(2):143-51.e7. PMID: 25861956.

[17]. Muthukrishnan A, Bijai Kumar L, Ramalingam G. Medication-related osteonecrosis of the jaw: a dentist's nightmare. BMJ Case Rep. $2016 \mathrm{Apr}$ 6;2016:bcr2016214626. PMID: 27053542.

[18]. Subha M, Arvind M. Role of magnetic resonance imaging in evaluation of trigeminal neuralgia with its anatomical correlation. Biomedical and Pharmacology Journal. 2019 Mar 25;12(1):289-96.

[19]. Patil SR, Maragathavalli G, Araki K, Al-Zoubi IA, Sghaireen MG, Gudipaneni RK, et al. Three-rooted mandibular first molars in a Saudi Arabian population: a CBCT study. PesquisaBrasileiraemOdontopediatria e ClinicaIntegrada. 2018 Aug 27;18(1):4133.

[20]. Choudhury P, Panigrahi RG, Maragathavalli, Panigrahi A, Patra PC. Vanishing roots: first case report of idiopathic multiple cervico-apical external root resorption. J ClinDiagn Res. 2015 Mar;9(3):ZD17-9. PMID: 25954713.

[21]. Rohini S, Kumar VJ. Incidence of dental caries and pericoronitis associated with impacted mandibular third molar-A radiographic study. Research Journal of Pharmacy and Technology. 2017;10(4):1081-4.

[22]. Dharman S, Muthukrishnan A. Oral mucous membrane pemphigoid - Two case reports with varied clinical presentation. J Indian SocPeriodontol. 2016 Nov-Dec;20(6):630-634. PMID: 29238145.

[23]. Subashri A, Maheshwari TN. Knowledge and attitude of oral hygiene practice among dental students. Research Journal of Pharmacy and Technology. 2016;9(11):1840-2.

[24]. Chandra P, Govindraju P. Prevalence of oral mucosal lesions among tobacco users. Oral Health Prev Dent. 2012;10(2):149-53. PMID: 22763594.

[25]. Bouquot JE, Gorlin RJ. Leukoplakia, lichen planus, and other oral keratoses in 23,616 white Americans over the age of 35 years. Oral Surg Oral Med Oral Pathol. 1986 Apr;61(4):373-81. PMID: 3458148.

[26]. Corbet EF, Holmgren CJ, Phillipsen HP. Oral mucosal lesions in 65-74-yearold Hong Kong Chinese. Community Dent Oral Epidemiol. 1994 Oct;22(5 Pt 2):392-5. PMID: 7835037.

[27]. Ismail SB, Kumar SK, Zain RB. Oral lichen planus and lichenoid reactions: etiopathogenesis, diagnosis, management and malignant transformation. J Oral Sci. 2007 Jun;49(2):89-106. PMID: 17634721.

[28]. Neville BW, Day TA. Oral cancer and precancerous lesions. CA Cancer J Clin. 2002 Jul-Aug;52(4):195-215. PMID: 12139232. 